\title{
The Role of Corporates in Governing Carbon Dioxide Removal: Outlining a Research Agenda
}

\author{
Francesca Battersby ${ }^{1,2 *}$, Richard J. Heap ${ }^{2}$, Adam C. Gray ${ }^{2}$, Mark Workman ${ }^{2,3}$ and \\ Finn Strivens ${ }^{2}$ \\ ${ }^{1}$ Centre for Environmental Policy, Imperial College London, London, United Kingdom, ${ }^{2}$ Foresight Transitions Ltd., Salisbury, \\ United Kingdom, ${ }^{3}$ Energy Futures Lab, Imperial College London, London, United Kingdom
}

OPEN ACCESS

Edited by:

Phil Renforth,

Heriot-Watt University,

United Kingdom

Reviewed by:

Miranda Boettcher,

German Institute for International and

Security Affairs (SWP), Germany

Matthias Honegger,

Perspectives Climate

Research gGmbH, Germany

${ }^{*}$ Correspondence:

Francesca Battersby

francesca.battersby18@imperial.ac.uk

Specialty section:

This article was submitted to

Negative Emission Technologies,

a section of the journal

Frontiers in Climate

Received: 27 March 2021

Accepted: 17 January 2022

Published: 10 February 2022

Citation:

Battersby F, Heap RJ, Gray AC, Workman $M$ and Strivens $F$ (2022) The

Role of Corporates in Governing Carbon Dioxide Removal: Outlining a Research Agenda.

Front. Clim. 4:686762.

doi: 10.3389/fclim.2022.686762
With 1,500 companies now estimated to have set net zero targets, corporate engagement with carbon dioxide removal (CDR) has gained substantial momentum. Yet despite the corporate sector becoming a key domain of CDR decision-making, corporates have not received research attention as influential actors in the governance of CDR. This paper provides a perspective on how corporates influence and enact de facto governance of CDR. We collate a preliminary evidence base regarding possible modes of CDR governance by corporates. Focusing on voluntary corporate engagement with CDR, we examine how and why firm-level decision-making takes place, and interrogate the implications of such activity. We find that the current literature focuses on technoeconomic attributes of CDR solutions as drivers of corporate engagement; however, the ability for corporates to formulate a (business) case for engaging with CDR is potentially shaped by a broader array of financial and non-financial factors that are currently overlooked. This gives corporates the influence to define what and how to govern, an inherently "political act." We finally highlight possible lenses for future research, noting lessons to be drawn from climate justice, anticipatory governance, responsible innovation, and futures literatures. These could provide a deepened understanding of the dynamics and implications of current de facto CDR governance, and allow this to be challenged where appropriate. Ultimately, without awareness and oversight of how CDR is being governed in the real world, policy and governance research may not be successful in driving us toward desired net zero futures.

Keywords: anticipatory governance, carbon dioxide removal, corporate climate practices, greenhouse gas removal, negative emission technologies, responsible research and innovation, climate governance

\section{INTRODUCTION}

Recent years have seen the adoption of "net zero" targets across the private sector, and in turn, the emergence of carbon dioxide removal (CDR) as a key tenet of many climate action strategies, complementing conventional mitigation. With 1,500 companies estimated to have set targets (Black et al., 2021), net zero has given relevance and momentum to CDR in the corporate sector.

Removals will require care if they are to be deployed as a climate solution-both to manage associated risks and capture benefits (Dooley and Kartha, 2017; Fuss et al., 2018; McLaren et al., 2019; Honegger et al., 2021a). This has given rise to a substantial literature examining CDR "governance." Governance will be integral to whether, when, how, where, and what CDR gets deployed, which will have implications for the climate, natural environment, economy, and civil society. 
As a key domain of CDR activity, the corporate sector requires examination as both a subject and object of governance. Yet at present, there is limited exploration in the CDR governance literature of how corporate involvement in CDR decision-making will shape outcomes. This governance research gap is made more concerning by gaps in real-world governance: despite playing an integral role in the delivery of $1.5^{\circ} \mathrm{C}$, corporate climate action is currently not subject to systematic oversight (Honegger et al., 2021b), in the same way as nations under the Paris Agreement.

This paper will therefore explore the current and possible future role of corporates in governing CDR. Through a rapid review of peer-reviewed literature, summarized in Table 1, we collate a preliminary evidence base regarding possible modes of CDR governance by corporates. We set these in the context of the wider CDR governance literature to interrogate the issues and potential implications of such activity. We finally highlight emergent lenses for thinking about this into the future, and how these might be applied to the overlooked question of corporates.

\section{CDR GOVERNANCE RESEARCH TO DATE Framings of CDR Governance}

$\mathrm{CDR}$ is described as requiring "responsible" governance (Bellamy, 2018), to ensure it is researched, developed, and deployed in a manner that maximizes beneficial and minimizes adverse outcomes. These encompass local-level impacts, for example on biodiversity and community wellbeing (Buck, 2016; Dooley and Kartha, 2017; Fuss et al., 2018), as well as system-level ones, like mitigation deterrence (McLaren, 2020), the transgression of planetary boundaries (Honegger et al., 2021a), and justice issues, for example international and intergenerational (Buck, 2018; Carton et al., 2021).

CDR governance has thus become the subject of much research, and takes on two broad frames in the literature. Firstly, governance is discussed as a means of structuring CDR activities to ensure they develop responsibly into the future. This body of literature spans from principle-based recommendations for CDR research (Rayner et al., 2013; Bellamy, 2018), to detailed examinations of policy options (Haszeldine et al., 2018; Honegger and Reiner, 2018). There is an extensive literature around this "preferred" governance, as we shall term it here (Lomax et al., 2015; Bellamy, 2016; McLaren et al., 2019).

Governance is also discussed as an "observed" system. Observed governance is examined in works like Geden et al. (2018), Cox and Edwards (2019), Boettcher (2020), Carton et al. (2020), and O'Beirne et al. (2020), in which historical and emergent interactions between incumbent governance architectures and CDR are considered. Going a step further, Gupta and Möller (2019) have described "de facto governance," as perhaps a subset of observed governance, whereby "sources of governance... are unacknowledged and unrecognized as seeking to govern, even as they exercise governance effects."

CDR is often seen as a "largely ungoverned space" (Gupta and Möller, 2019). Yet de facto governance may be critical to shaping outcomes, and thus demands research attention. It is worth observing how CDR governance is constructed through the activities of "real world" actors, and examining whether this deviates from "preferred" systems.

\section{Corporates as Governance Actors in CDR}

The current CDR discourse is highly techno-centric. However, there is a growing voice calling for narratives to be based around socio-technical constructs (Bellamy, 2016; Sovacool, 2021), acknowledging that technical elements of CDR cannot be considered independent of their social context- "the production, distribution and use of technology" (Geels, 2004). It is through this frame that the role of corporates becomes relevant. Corporate organizations are defined herein as large, for-profit companies, typically with a multinational presence, whose primary activity is not historically related to CDR.

The corporate sector faces pressure in the changing regulatory and market environment to reduce its contribution to climate change (FSB-TCFD, 2017). In this context, there is an increasingly clear argument for corporates to concern themselves with both the realization of CDR solutions and the mainstreaming of their use. Indeed, as the need for CDR is clarified at a societal level, corporate engagement may take on an anticipatory dimension-companies may "want to become active and front-run potentially emerging policies" (Honegger et al., 2021b). Corporates are thus inherent to CDR's "socio-technical system."

Recent years have seen corporates become investors in and buyers of removals (Muttitt, 2021), and embed themselves in decision-making about solution development and deployment. In doing so, they become central to the construction and dissemination of knowledge of CDR. Notably, a recent Comment piece published in Nature by the team behind Microsoft's CDR strategy outlines the governance developments needed to unlock further corporate action by corporates (Joppa et al., 2021). A CDR sector may already be emerging in this way from the "bottom up" (Bellamy and Geden, 2019).

Yet corporate interest in CDR is not purely a climate play. While climate and sustainability objectives have increasing weight in corporate decision-making, these sit within the broader

TABLE 1 | Search details for rapid literature review.

\begin{tabular}{|c|c|c|c|}
\hline Databases searched & $\begin{array}{l}\text { Carbon dioxide removal } \\
\text { terms }\end{array}$ & AND corporates terms & Other search details \\
\hline $\begin{array}{l}\text { Web of Science-All Databases, } \\
\text { article reference lists }\end{array}$ & $\begin{array}{l}\text { "Carbon dioxide removal" OR } \\
\text { "carbon removal" OR } \\
\text { "greenhouse gas removal" OR } \\
\text { "negative emission" }\end{array}$ & $\begin{array}{l}\text { Corporate OR company OR } \\
\text { companies OR private OR } \\
\text { "private sector" OR business OR } \\
\text { industry }\end{array}$ & 2010-present \\
\hline
\end{tabular}


fiduciary duty of corporates directors to ensure a company's success. It is therefore worth examining how the distinct agendas of corporate governance and CDR governance interact.

\section{OBSERVING HOW CORPORATES INFLUENCE AND ENACT CDR GOVERNANCE}

The "observed" role of corporates in shaping CDR governance has been examined to a limited degree in research settings. This section offers a brief overview of this literature, to generate perspectives on the governing role of corporates in the current landscape.

\section{Firm-Level Decision-Making}

Platt et al. (2018) assert that "in many developed nations, the main drivers of decarbonisation are taking place in liberalized markets-comprising private firms making decisions about how to compete in open markets." If this is true, greater attention ought to be paid to how CDR decisions are informed at the firm level. Given that much CDR engagement by corporates today is voluntary (Honegger et al., 2021b), trends in firm preferences around, for example, solution options, financing approaches, and implementation strategies, exert a powerful structuring force on the CDR market. Research into firm-level decision-making can thus begin to anticipate these trends.

Platt et al. (2018) examine firm-level decision-making by assessing revenue-generating and cost-avoiding opportunities in CDR, evaluating the extent to which these might induce corporates to engage with CDR value chains. This technoeconomic framing is echoed across the literature (Lomax et al., 2015; Nemet, 2018; Cox and Edwards, 2019; Izikowitz, 2021). Of course, in the absence of a regulatory requirement for corporate CDR, a clear business case is typically needed to stimulate engagement. However, other social drivers are relevant and contribute to such a "case" - such as a "sense of responsibility [for historical carbon]... and consumer and shareholder preferences" (Rodriguez et al., 2021), regulatory expectations, reputational interests, risk avoidance, and corporate purpose (South Pole, 2021). The "case" for CDR may not involve immediate, if any, financial return.

Limited work has been done to anticipate how firm-level decisions might translate to CDR outcomes. Buck (2018) considers how vested corporate interests in specific solutionssuch as fossil fuel companies' interest in direct air capture for enhanced oil recovery-will influence the scale at which solutions are realized. This will have physical implications (for example for local communities, or regional resource use), but also political ones, allowing corporates to shape "commercialization strategies" and thus construct the paradigm under which CDR is used (in this case favoring carbon utilization over storage and removal).

Corporates may even define the very object to be governed. Corporate claims and strategies make a discursive contribution to governance, particularly by shaping what is and is not CDR. The inherently "political act" of categorization (Gupta and Möller, 2019) may reverberate through the modes, rationales, and influential "speakers," that all contribute to a resultant governance system (Boettcher, 2020; Boettcher and Kim, 2021).

\section{Decision-Making in the Context of Policy}

There is also merit in observing how corporates interact with policy, to produce new, or reinforce old, forms of governance. Honegger et al. (2021b) examine how corporate initiatives can complement policy mixes to address "CDR-specific policy design needs," considering some of today's major corporate initiatives by Microsoft, Shopify, Stripe, and Swiss Re. Key insights include the below.

1. Corporates could be instrumental in down-costing CDR. This (albeit small) sample of large corporates have demonstrated surprising willingness to pay high upfront costs for solutions, particularly those with higher levels of permanence.

2. Corporate CDR purchases are not systematically overseen, which could lead to issues like double counting. A comprehensive insurance framework for non-permanence is not yet in place, despite many traded credits involving biospheric storage.

3. Corporate purchases of CDR credits may not align with the Paris Agreement, if these risks are not managed.

Honegger et al. (2021b) also highlight diverging rationales for engagement, comparing corporates pursuing an earlymover approach by commercializing new technologies at significant cost, with those pursuing a "quick-fix corporate social responsibility" route by purchasing low-cost credits that may lack integrity. These differing rationales, and corresponding modes of engagement, highlight a potential need for policy intervention to address this divergence. Joppa et al. (2021) detail the need for (1) standardization of net zero, (2) robust measurement and accounting protocols, and (3) incentives that reward higherintegrity approaches, to address these "bugs" in the current voluntary system.

Schenuit et al. (2021) assess CDR policymaking in nine OECD countries, finding a correlation between the level of private sector engagement and the state of CDR development. Though the authors do not directly comment on the relationship between corporate activity and governance, they provide a useful framework to track governance development. Highlighting five key dimensions of CDR policy, each sitting on a continuum of possible manifestation, the authors use combinations of these possibilities to describe three possible policymaking "types," outlined in Table 2. These continua could be used to assess corporate policy preferences, and track how these are reflected in the emergent CDR governance paradigm.

\section{Possible Analogs for Corporate Climate Engagement-Why CDR Is Distinct}

Governance analogs can be found with CCS, forestry, bioenergy, and other renewables literatures (Carton et al., 2020). Yet while these works illuminate some key influences on corporate behavior, CDR solutions have distinct attributes that will shape corporate engagement. Primarily, the business case for removals is more complex: there are few markets in which the act of removal itself is rewarded (Cox and Edwards, 2019; 
TABLE 2 | Empirically identified dimensions of CDR policymaking and continua of how these dimensions manifest, adapted from Schenuit et al. (2021).

\begin{tabular}{llll}
\hline Dimensions & Continua & $\begin{array}{l}\text { I. Incremental } \\
\text { modification }\end{array}$ & $\begin{array}{l}\text { II. Early integration } \\
\text { and fungibility }\end{array}$ \\
\hline $\begin{array}{l}\text { CDR in mitigation targets } \\
\text { View of CDR among actors } \\
\text { of the incumbent regime } \\
\text { CDR methods addressed }\end{array}$ & $\begin{array}{l}\text { Fungible-Strictly separated } \\
\text { Proactive integration-Restrained } \\
\text { integration } \\
\text { Only ecosystem-based-Wide range } \\
\text { of methods }\end{array}$ & $\begin{array}{l}\text { Strictly separated } \\
\text { Restrained integration }\end{array}$ & $\begin{array}{l}\text { Fungible } \\
\text { Proactive integration }\end{array}$ \\
$\begin{array}{l}\text { Relation of CDR policy } \\
\text { instruments to broader } \\
\text { limate policy mix }\end{array}$ & Incremental opening-Full integration \\
$\begin{array}{l}\text { Government support for } \\
\text { developing CDR niches }\end{array}$ & $\begin{array}{l}\text { Limited support-Nurturing and } \\
\text { empowering }\end{array}$ & Limited support & $\begin{array}{l}\text { Focus on } \\
\text { ecosystem-based }\end{array}$ \\
\hline
\end{tabular}

The three final columns describe different policymaking "types" that could arise from different manifestations.

Schenuit et al., 2021), and the per-ton cost varies significantly across solutions. Moreover, cost-minimization and commercial opportunity are likely not the only factors driving corporate action on CDR (Honegger et al., 2021b) - as per section FirmLevel Decision-Making.

Several parallels between traditional carbon markets, on which there is an extensive literature, and nascent removals markets are instructive here. Firstly, the "integrity" of traded credits has been hotly debated, encompassing questions about additionality (Michaelowa et al., 2019), measurement (Schwartzman et al., 2021), and social and environmental safeguarding of projects (Carton et al., 2020)-these issues will continue to be relevant for CDR (Carbon Direct Microsoft, 2021). Secondly, questions around the legitimate use of credits are increasingly raised by commentators-namely, how abatement challenges relate to offset need (Allen et al., 2020; Science Based Targets Initiative (SBTi), 2021). This experience has elevated corporate awareness of credit integrity issues, and the desire to avoid reputational damage stemming from "greenwashing" allegations may become more important in future decision-making. This potentially underpins corporate willingness to overpay for removals perceived as less risky (Honegger et al., 2021b).

Importantly, though, corporate CDR engagement is not bounded by the market-in fact, the market opportunity is currently limited, with CDR credits in poor supply (Zelikova, 2020). Corporates can alternatively engage through research (both technical and non-technical), knowledge sharing, even advocacy (Carbon Direct Microsoft, 2021; Joppa et al., 2021). De facto governance research should be alert to these possibilities. Understanding how corporates respond to financial and non-financial drivers, within and beyond the market, will be important for understanding how and why corporates govern CDR.

\section{WHAT ROLE FOR CORPORATES IN FUTURE CDR GOVERNANCE?}

\section{Good Governance}

Has any research been done to examine how corporates could and should behave with regard to, and indeed govern, CDR? Much of the "preferred governance" literature suggests that corporates should continue to play a role in future CDR decision-making, namely by investing in the development of, and guaranteeing demand for, solutions (Lomax et al., 2015; Haszeldine et al., 2018; Platt et al., 2018). Indeed, corporates are well-positioned to accelerate the urgently needed scale-up of CDR solutions, particularly where the right policy support is in place (Joppa et al., 2021). However, this techno-economic framing of governance overlooks the socio-political influence afforded to corporates in such systems, highlighted by Buck (2018) (see section Firm-Level Decision-Making). This challenges the notion that the role of corporates in CDR governance is simply to mobilize finance to solutions, with policy having overarching control. Being more deliberate about what, why, and how to incentivise corporates will be important for managing these socio-political influences toward a preferred outcome (Bellamy, 2018).

Some works have sought to define "good" corporate CDR behavior in the context of net zero. Smith (2020) and Rogelj et al. (2021) provide principle-based frameworks for emitters. These focus on transparency-recommending that corporates disclose the extent of removal relative to abatement, and the type of solutions and storage used. The recent SBTi Corporate Net-Zero Standard (Science Based Targets Initiative (SBTi), 2021) provides more formal criteria, for example regarding CDR quantity (requiring that companies remove and permanently store any emissions "that remain once companies have achieved their long-term science-based target"), and promotes "beyond value chain mitigation" activities like "investing in direct air capture (DAC) and geologic storage." Nonetheless, the technoeconomic framing persists-the Standard governs corporate investment and purchasing decisions, without recognizing their wider normative influence. With net zero ill-defined (Joppa et al., 2021), the current governance of corporate CDR activity itself remains a "wild west."

\section{Lenses for Examining Corporate CDR Governance in Future Research}

How, then, might a research agenda around corporate CDR governance might be shaped? This section provides some 
suggestions for advancing the observed and preferred governance literature to better account for the role of corporates.

Framings of justice are increasingly adopted in climate and CDR dialogues, and could be helpful for thinking about the role of corporates in "preferred" CDR governance. Works like Fyson et al. (2020), Morrow et al. (2020), Pozo et al. (2020), Batres et al. (2021), and Carton et al. (2021) highlight where injustices might arise-considering for example geographical, temporal, and sectoral distributions of CDR activity-and provide principles for just CDR policymaking, such as the use of mitigation hierarchies, mixed solution portfolios, and criteria to evaluate the local and systemic impacts of projects. These insights could inform "best practice" approaches at the firm or standard-setting level, by expanding understandings of CDR's far-reaching justice implications and seeking to proactively manage them [this type of thinking is evident in Lenzi et al. (2021)].

Before we examine how corporates should govern CDR, we must better understand the nature and implications of their de facto role. This paper has provided a preliminary view of where issues might arise, but a more systemic approach to evaluating current governance dynamics and predicting future developments, using knowledge available today, is needed. This thinking is embodied in literatures around anticipatory governance and responsible innovation, which are increasingly being applied to climate solutions (Vervoort and Gupta, 2018; Low and Buck, 2020; Muiderman et al., 2020). These frameworks provide an opportunity to reflect on the development of new techno-scientific fields, and through the introduction of new narratives and framings, challenge and reshape trajectories of development in line with preferred futures (Low and Buck, 2020). Thinking about net zero not as a singular outcome, but in terms of different possible futures, which corporates will be instrumental in shaping through their actions on both abatement and $\mathrm{CDR}$, might provide some clarity on the interventions required to make desired outcomes possible.

\section{CONCLUSION}

Though technical and economic decisions are the focal point of the corporate $\mathrm{CDR}$ discussion, corporates have an unrecognized socio-political influence: both in terms of how and why they make seemingly techo-economic decisions (the CDR strategies they adopt will shape both the physical and political landscape), but also in how they engage with CDR outside these boundaries, for example in how they construct and disseminate CDR knowledge. Corporates are already governing CDR in this way from the bottom up.

\section{REFERENCES}

Allen, M., Axelsson, K., Caldecott, B., Hale, T., Hepburn, C., Hickey, C., et al. (2020). The Oxford Principles for Net Zero Aligned Carbon Offsetting. Available online at: https:/www.smithschool.ox.ac.uk/publications/reports/ Oxford-Offsetting-Principles-2020.pdf (accessed November 14, 2021).

Batres, M., Wang, F. M., Buck, H., Kapilad, R., Kosar, U., Lickere, R., et al. (2021). Environmental and climate justice and technological
The de facto governing role of corporates ought to be better reflected in the literature. When observing governance, metrics are needed to assess the nature and implications of corporate CDR activity. Researchers and policymakers also need to engage directly with corporates to understand their motivations and internal decision-making structures, to better anticipate corporate preferences, and how these might shape the future CDR landscape. On preferred governance, commentators should seek to evaluate governance holistically, rather than atomistically-considering different possible governance paradigms, how different actors might take decisions within these, and whether these outcomes would be acceptable to society. Discourses around climate and CDR justice may provide helpful tenets for thinking about the implications of corporate CDR activity, strengthening preferred governance work by bolstering rationales of why to govern. Both bodies of literature could be advanced through the adoption of theoretical lenses such as anticipatory governance and responsible innovation. These would allow commentators to examine corporate $\mathrm{CDR}$ governance as it emerges, anticipate future outcomes, and potentially become part of governance itself by challenging dominant constructs and introducing new narratives better aligned with desired futures.

This paper has provided a brief perspective on potential de facto CDR governance by corporates, finding that corporates' potential to influence and enact governance has been viewed too narrowly to date, risking inadequate "political oversight" of how CDR is developing (Gupta and Möller, 2019) and necessitating greater research attention and new approaches. Being alert to the role of corporate decision-making is critical to ensuring the extensive body of research into how CDR should be governed is not made redundant by powerful de facto influences.

\section{AUTHOR CONTRIBUTIONS}

$\mathrm{FB}, \mathrm{RH}, \mathrm{AG}$, and MW contributed to the conception and design of the study. FB and FS led the drafting of the paper. All authors contributed to manuscript revision, read, and approved the submitted version.

\section{FUNDING}

Funding for this research was provided to Foresight Transitions by the European Climate Foundation, Grant Number DG-200560546.

carbon removal. Electr. J. 34, 107002. doi: 10.1016/j.tej.2021. 107002

Bellamy, R. (2016). A sociotechnical framework for governing climate engineering. Sci. Technol. Human Values. 41, 135-162. doi: 10.1177/0162243915591855

Bellamy, R. (2018). Incentivize negative emissions responsibly. Nat. Energy. 3, 532-534 doi: 10.1038/s41560-018-0156-6

Bellamy, R., and Geden, O. (2019). Govern $\mathrm{CO}_{2}$ removal from the ground up. Nat. Geosci. 12, 874-876. doi: 10.1038/s41561-019-0475-7 
Black, R., Cullen, K., Fay, B., Hale, T., Lang, J., Mahmood, S., et al. (2021). Taking Stock: A Global Assessment of Net Zero Targets, Energy and Climate Intelligence Unit and Oxford Net Zero. Available online at: https://cal-eci.edcdn.com/ reports/ECIU-Oxford_Taking_Stock.pdf?v=1616461369 (accessed November 7, 2021).

Boettcher, M. (2020). Coming to GRIPs with NETs discourse: implications of discursive structures for emerging governance of negative emissions technologies in the UK. Front. Clim. 2, 595685. doi: 10.3389/fclim.2020.595685

Boettcher, M., and Kim, R. E. (2021). Arguments and architectures: discursive and institutional structures shaping global climate engineering governance. Environ. Sci. Policy 128, 121-131. doi: 10.1016/j.envsci.2021. 11.015

Buck, H. J. (2016). Rapid scale-up of negative emissions technologies: social barriers and social implications. Clim. Change. 139, 155-167. doi: 10.1007/s10584-016-1770-6

Buck, H. J. (2018). The politics of negative emissions technologies and decarbonization in rural communities. Global Sustain. 1, 1-7. doi: $10.1017 /$ sus.2018.2

Carbon Direct and Microsoft (2021). Criteria for High-Quality Carbon Dioxide Removal. Available online at: https://query.prod.cms.rt.microsoft.com/cms/ api/am/binary/RWGG6f (accessed November 25, 2021).

Carton, W., Asiyanbi, A., Beck, S., Buck, H. J., and Lund, J. F. (2020). Negative emissions and the long history of carbon removal. WIREs Clim. Change. 11, 671. doi: 10.1002/wcc.671

Carton, W., Lund, J. F., and Dooley, K. (2021). Undoing equivalence: rethinking carbon accounting for just carbon removal. Front. Clim. 3, 664130doi: 10.3389/fclim.2021.664130

Cox, E., and Edwards, N. R. (2019). Beyond carbon pricing: policy levers for negative emissions technologies. Clim. Policy 19, 1144-1156. doi: 10.1080/14693062.2019.1634509file

Dooley, K., and Kartha, S. (2017). Land-based negative emissions: risks for climate mitigation and impacts on sustainable development. Int. Environ. Agreements 18, 79-98. doi: 10.1007/s10784-017-9382-9

FSB-TCFD (2017). Final Report: Recommendations of the Task Force on Climaterelated Financial Disclosures. Available online at: https://assets.bbhub. io/company/sites/60/2021/10/FINAL-2017-TCFD-Report.pdf (accessed November 7, 2021).

Fuss, S., Lamb, W. F., Callaghan, M. W., Hilaire, J., Creutzig, F., Amann, T., et al. (2018). Negative emissions-Part 2: costs, potentials and side effects. Environ. Res. Lett. 13, 063002. doi: 10.1088/1748-9326/aabf9f

Fyson, C. L., Baur, S., Gidden, M., and Schleussner, C.-F. (2020). Fair-share carbon dioxide removal increases major emitter responsibility. Nat. Clim. Change. 10, 836-841 doi: 10.1038/s41558-020-0857-2

Geden, O., Scott, V., and Palmer, J. (2018). Integrating carbon dioxide removal into EU climate policy: prospects for a paradigm shift. WIREs Clim. Change. 9, 521. doi: $10.1002 /$ wcc. 521

Geels, F. (2004). From sectoral systems of innovation to socio-technical systems: Insights about dynamics and change from sociology and institutional theory. Res. Policy. 33, 897-920. doi: 10.1016/j.respol.2004.01.015

Gupta, A., and Möller, I. (2019). De facto governance: how authoritative assessments construct climate engineering as an object of governance. Env. Polit. 28, 480-501. doi: 10.1080/09644016.2018.1452373

Haszeldine, R. S., Flude, S., Johnson, G., and Scott, V. (2018). Negative emissions technologies and carbon capture and storage to achieve the Paris Agreement commitments. Phil. Trans. R. Soc. A. 376, 20160447. doi: 10.1098/rsta.2016.0447

Honegger, M., Michaelowa, A., and Roy, J. (2021a). Potential implications of carbon dioxide removal for the sustainable development goals. Clim. Policy 21, 678-698. doi: 10.1080/14693062.2020.1843388

Honegger, M., Poralla, M., Michaelowa, A., and Ahonen, H.-M. (2021b). Who is paying for carbon dioxide removal? designing policy instruments for mobilizing negative emissions technologies. Front. Clim. 3, 672996. doi: 10.3389/fclim.2021.672996

Honegger, M., and Reiner, D. (2018). The political economy of negative emissions technologies: consequences for international policy design. Clim. Policy 18, 306-321. doi: 10.1080/14693062.2017.1413322

Izikowitz, D. (2021). Carbon purchase agreements, dactories, and supplychain innovation: what will it take to scale-up modular direct air capture technology to a gigatonne scale. Front. Clim. 3, 636657. doi: 10.3389/fclim.2021. 636657
Joppa, L., Luers, A., Willmott, E., Friedmann, S. J., Hamburg, S. P., and Broze, R. (2021). Microsoft's million-tonne $\mathrm{CO}_{2}$-removal purchase-lessons for net zero. Nature. 597, 629-632. doi: 10.1038/d41586-021-02606-3

Lenzi, D., Jakob, M., Honegger, M., Droege, S., Heyward, J. C., and Kruger, T. (2021). Equity implications of net zero visions. Clim. Change. 169, 20. doi: 10.1007/s10584-021-03270-2

Lomax, G., Workman, M., Lenton, T., and Shah, N. (2015). Reframing the policy approach to greenhouse gas removal technologies. Energy Policy. 78, 125-136. doi: 10.1016/j.enpol.2014.10.002

Low, S., and Buck, H. J. (2020). The practice of responsible research and innovation in "climate engineering". WIREs Clim. Change. 11, 644. doi: 10.1002/wcc.644

McLaren, D. (2020). Quantifying the potential scale of mitigation deterrence from greenhouse gas removal techniques. Clim. Change 162, 2411-2428. doi: 10.1007/s10584-020-02732-3

McLaren, D. P., Tyfield, D. P., Willis, R., Szerszynski, B., and Markusson, N. O. (2019). Beyond "Net-Zero": a case for separate targets for emissions reduction and negative emissions. Front. Clim. 1, 4. doi: 10.3389/fclim.2019.00004

Michaelowa, A., Hermwille, L., Obergassel, W., and Butzengeiger, S. (2019). Additionality revisited: guarding the integrity of market mechanisms under the Paris Agreement. Clim. Policy. 19, 1211-1224. doi: 10.1080/14693062.2019.1628695

Morrow, D. R., Thompson, M. S., Anderson, A., Batres, M., Buck, H. J., Dooley, K., et al. (2020). Principles for thinking about carbon dioxide removal in just climate policy. One Earth. 3, 150-153. doi: 10.1016/j.oneear.2020.07.015

Muiderman, K., Gupta, A., Vervoort, J., and Biermann, F. (2020). Four approaches to anticipatory climate governance: different conceptions of the future and implications for the present. WIREs Clim. Change. 11:673. doi: 10.1002/wcc.673

Muttitt, G. (2021). Net Expectations: Assessing the Role of Carbon Dioxide Removal in Companies' Climate Plans. Greenpeace, UK. Available online at: https:// www.greenpeace.org.uk/wp-content/uploads/2021/01/Net-ExpectationsGreenpeace-CDR-Briefing-updated2.pdf (accessed October 24, 2021).

Nemet, G. F. (2018). Negative emissions-Part 3: Innovation and upscaling. Environ. Res. Lett. 13, 063003. doi: 10.1088/1748-9326/aabff4

O'Beirne, P., Battersby, F., Mallett, A., Aczel, M., Makuch, K., Workman, M., et al. (2020). The UK net-zero target: Insights into procedural justice for greenhouse gas removal. Environ. Sci. Policy 112, 264-274. doi: 10.1016/j.envsci.2020.06.013

Platt, D., Workman, M., and Hall, S. (2018). A novel approach to assessing the commercial opportunities for greenhouse gas removal technology value chains: developing the case for a negative emissions credit in the UK. J. Clean. Prod. 203, 1003-1018. doi: 10.1016/j.jclepro.2018.08.291

Pozo, C., Galán-Martín, Á., Reiner, D. M., Mac Dowell, N., and Guillén-Gosálbez, G. (2020). Equity in allocating carbon dioxide removal quotas. Nat. Clim. Change. 10, 640-646. doi: 10.1038/s41558-020-0802-4

Rayner, S., Heyward, C., Kruger, T., Pidgeon, N., Redgwell, C., and Savulescu, J. (2013). The oxford principles. Clim. Change. 121, 499-512. doi: 10.1007/s10584-012-0675-2

Rodriguez, E., Lefvert, A., Fridahl, M., Grönkvist, S., Haikola, S., and Hansson, A. (2021). Tensions in the energy transition: Swedish and Finnish company perspectives on bioenergy with carbon capture and storage. J. Clean. Prod. 280, 124527. doi: 10.1016/j.jclepro.2020.124527

Rogelj, J., Geden, O., Cowie, A., and Reisinger, A. (2021). Net-zero emissions targets are vague: three ways to fix. Nature 591, 365-368. doi: 10.1038/d41586-021-00662-3

Schenuit, F., Colvin, R., Fridahl, M., McMullin, B., Reisinger, A., Sanchez, D. L., et al. (2021). Carbon dioxide removal policy in the making: assessing developments in 9 OECD cases. Front. Clim. 3, 638805. doi: 10.3389/fclim.2021.638805

Schwartzman, S., Lubowski, R. N., Pacala, S. W., Keohane, N. O., Kerr, S., Oppenheimer, M., et al. (2021). Environmental integrity of emissions reductions depends on scale and systemic changes, not sector of origin. Environ. Res. Lett. 16, 091001. doi: 10.1088/1748-9326/ac18e8

Science Based Targets Initiative (SBTi) (2021). SBTi Corporate Net-Zero Standard. Availble online at: https://sciencebasedtargets.org/resources/files/Net-ZeroStandard.pdf (accessed November 25, 2021).

Smith, S. (2020). A case for transparent net-zero carbon targets. Commun. Earth Environ. 2, 24. doi: 10.1038/s43247-021-00095-w

South Pole (2021). The Push and Pull of Net Zero: Drivers of Climate Action. Available online at: https://www.southpole.com/publications/the-push-andpull-of-net-zero-download (accessed October 29, 2021) 
Sovacool, B. K. (2021). Reckless or righteous? Reviewing the sociotechnical benefits and risks of climate change geoengineering. Energy Strategy Rev. 35, 100656. doi: 10.1016/j.esr.2021.100656

Vervoort, J. M., and Gupta, A. (2018). Anticipating climate futures in a $1.5^{\circ} \mathrm{C}$ era: the link between foresight and governance. Curr. Opin. Environ. Sustain. 31, 104-111. doi: 10.1016/j.cosust.2018.01.004

Zelikova, J. (2020). In Search of Carbon Removal Offsets. Carbon. Available online at: https://carbon180.medium.com/in-search-of-carbon-removal-offsets42abf71b3ccc (accessed November 25, 2021).

Conflict of Interest: FB, RH, AG, MW, and FS were under contract to the company Foresight Transitions Ltd., at the time this research was undertaken. The European Climate Foundation helped to guide the research questions and objectives, but had no influence over the outcomes.
Publisher's Note: All claims expressed in this article are solely those of the authors and do not necessarily represent those of their affiliated organizations, or those of the publisher, the editors and the reviewers. Any product that may be evaluated in this article, or claim that may be made by its manufacturer, is not guaranteed or endorsed by the publisher.

Copyright (c) 2022 Battersby, Heap, Gray, Workman and Strivens. This is an openaccess article distributed under the terms of the Creative Commons Attribution License (CC BY). The use, distribution or reproduction in other forums is permitted, provided the original author(s) and the copyright owner(s) are credited and that the original publication in this journal is cited, in accordance with accepted academic practice. No use, distribution or reproduction is permitted which does not comply with these terms. 